\title{
Morphology and Immunohistochemistry of Thymus in Haysex Brown Cross Chickens
}

\author{
Svitlana Huralska ${ }^{1}$, Tetiana $\mathrm{Kot}^{1}$, Vasyl Koziy ${ }^{2 *}$, Vasyl Sokolyuk ${ }^{1}$, and Zoriana Khomenko ${ }^{1}$ \\ ${ }^{I}$ Zhytomyr National Agroecological University, Staryi Blvd., 7, Zhytomyr, 10008, Ukraine \\ ${ }_{2}^{2}$ Bila Tserkva National Agrarian University Sq. Soborna, 8/1, Belaya Tserkov, Kyiv region, 09100, Ukraine
}

*Corresponding author's Email: vasyl.koziy@ btsau.edu.ua; ORCID: 0000-0003-1364-9047

Received: 03 Aug. 2020

Accepted: 09 Sept. 2020

\begin{abstract}
Thymus plays an important role in the development and regulation of immune responses and other physiological processes. The present study aimed to examine the morphological and immunohistochemical changes of the thymus in Haysex Brown cross chickens with regard to their age. The morphofunctional studies of thymus were performed to determine and analyze age-related changes in anatomical (absolute and relative thymus mass), histological (area of the thymus cortex and medulla, area of connective tissue base, cortex index, number of thymic corpuscles in the lobule), and immunohistochemical (subpopulations of lymphocytes with surface markers $\mathrm{CD} 4^{+}$and $\mathrm{CD} 8^{+}$and their differentiation status) indexes. The study demonstrated that maximum morphological development of thymus could be observed in 20 and 40-day-old chickens. Up to 20 days of age, thymus mass increased proportionally with the chicken body weight. The results indicated that 40-day-old chickens had 1.46 times increase in the cortex index, compared to 20-day-old birds and 1.82 times compared to 8-day-old birds. An increase in the density and number of T-lymphocytes with surface markers $\left(\mathrm{CD}^{+}\right)$and was evident through aging. Regarding aging-associated alternations, the differentiation index $\left(\mathrm{CD}^{+}: \mathrm{CD}^{+}\right.$ratio) reached 1.26 $\pm 0.09,1.52 \pm 0.25$, and 1.56 \pm 0.23 in 40, 90, and 110-day-old chickens, respectively. The histological and cell parameters of the thymus in clinically healthy chickens can be used as indicators of normal functioning and to diagnose immunodeficiency in birds.
\end{abstract}

Keywords: CD8 Positive Lymphocytes, CD4 Positive Lymphocytes, Chickens, Cortex Index, Thymus, Immunohistochemical Characteristics

\section{INTRODUCTION}

The poultry industry is one of the promising areas of agriculture (Sharma, 1999). However, the resistance of birds to various diseases depends on their immune system status. One of the main organs of the immune system is thymus. The thymus is the central organ of the immune system. It is responsible for the maturation and differentiation of T-lymphocytes. T-cells are the main providers of the cellular immunity response (Kannan et al., 2015; Ali, 2017). Thymus in the early stages of ontogenesis controls and directs the structural and functional maturation of immunocompetent cells, and it ensures the safety and feasibility of immunological reactions in the later stages (Rezzani et al., 2008). The thymus, in addition to its role as primary lymphoid tissue, functions as a secondary lymphoid organ and is directly involved in the formation of immune competence in poultry (Rieker et al., 1995; Song et al., 2012; Mullakaev et al., 2013; Treesh et al., 2014).

Among all lymphoid organs, the thymus is the most histologically heterogeneous one. It contains both lymphoid and epithelial components, which makes it unique among all organs of the immune system (Senapati et al., 2015). Moreover, the thymus is rich in the number of cells with various neuroendocrine functions (Oubre et al., 2004). An investigation into the thymus functions of productive birds can contribute to the evaluation of their stress level and diet appropriateness. The chicken's maturation is accompanied by the increases of cytokinelike molecules responsible for the restoration of immune homeostasis in post-stress (Franchini et al., 2004). Both the excess and the lack of certain nutrients in the chickens may increase oxidative stress with characteristic changes 
in the expression of cytokines in the thymus cells (Wang et al., 2016; Li et al., 2018).

Therefore, this study investigated the morphological changes in the thymus of Haysex Brown cross chickens at different ages, which can be considered an important issue for the reassessment of the feeding and growing methods and act as the protocol of preventive treatments in industrial poultry farming.

\section{MATERIALS AND METHODS}

\section{Ethical approval}

All animal experiments were conducted in accordance with the Law of Ukraine "On the Protection of Animals from Brutal Treatment" and the recommendations of the Directive 2010/63/EU of the European Parliament and of the Council of 22 September 2010 on the protection of animals used for scientific purposes.

\section{Animals and study design}

The sample in this study was composed of 70 female chickens of Haysex Brown cross, aged 1 day. They were selected and raised in the conditions of the chicken farm "Solotvinsk Poultry Factory" Berdychiv district, Zhytomyr region Ukraine. The preventive vaccination was not provided for the tested birds. The bodyweight of birds was determined on the scales PS $6000 / \mathrm{C} / 2$. At different ages (i.e., 8, 20, 40, 90, and 110 days of age), the chickens (14 chickens per each age group) were euthanized by acute bleeding after ether anesthesia. After slaughtering, the thymus was detached and weighed on laboratory scales PS $1000 / \mathrm{C} / 2$.

For histological studies, each thymus was divided into the smaller tissue specimens and they were fixed in $10-12 \%$ aqueous solution of neutral formalin and Carnoy's fluid. After fixation, tissue specimens were washed with running tap water for 24-48 hours. In the next step, they were dehydrated in ethyl alcohol with increasing concentrations to $40,70,96$, and $100 \%$. Afterwards, the tissue specimens were embedded in paraffin blocks. Histological sections with a thickness of 5-8 $\mu \mathrm{m}$ were produced on a Luge scrotom MS-2. The sections were stained with hematoxylin and eosin and Van Gieson (Horalskyi et al., 2011).

To further the study, morphometric methods were used to obtain objective data about the structural organization of the thymus in chickens. Morphometric analysis was carried out using light microscopes MBS-10 (Russia), Micros MC-50 (Austria). The ratio of cortex and medulla area of the thymus and connective tissue framework was calculated using an ocular grid (square mesh panels) mounted in the eyepiece of the microscope. The percentage of the desired indicator was determined by calculating the ratio of the occupied and total area. Therefore, it was necessary to count the squares occupied by the examined structures in all chickens at the same magnification. The cortex index (CI) was defined as the ratio of cortex and medulla areas. The number of thymic corpuscles in the slice (at magnification $\times 100$ ) was counted in 15 fields of view (Horalskyi et al., 2011).

Immunohistochemical study was performed at the pathological laboratory, CSD Health Care, Kiev, Ukraine. The $\mathrm{CD}^{+}$( $\mathrm{T}$ helper) and $\mathrm{CD}^{+}$( $\mathrm{T}$ cytotoxic) cells in paraffin sections were counted using monoclonal antibodies and visualization system (all reagents were of the "DAKO" firm, Denmark). Briefly, the studied tissue specimens were fixed in a $10 \%$ solution of buffering neutral formalin (Fixx Shandon, USA) for 24 hours. After dehydration, the tissue specimens were embedded in pure paraffin wax with polymer additives (Richard-Allan Scientific, USA) at a temperature not more than $60{ }^{\circ} \mathrm{C}$. The tissue specimens were cut with a thickness of $5 \mu \mathrm{m}$ from paraffin blocks on a rotational scrotom Microm HM325 (Carl Zeiss, Germany), which were mounted on glass slides (Menzel, Germany) and then stained with hematoxylin and eosin (Kaltek, Italy). For further immunohistochemical studies, paraffin sections were placed on adhesive glass (Super Frost Plus, Menzel, Germany). The study was performed on deparaffined and rehydration slices.

To visualize the tissue antigens, the thermal section processing method in Target Retrieval Solution High $\mathrm{pH}$ (DAKO, Denmark) was employed through exposing the treatment in PT Modul (Dako, Denmark) for 32 min at 98$99^{\circ} \mathrm{C}$. The primary antibodies were applied after blocking non-specific protein binding by protein block (Diagnostic Biosystems, USA) and endogenous peroxidase activity by peroxidase block (Diagnostic Biosystems, USA). The DAKO EnVision FLEX+ detection system (DAKO, Denmark) was used to visualize primary antibodies. To visualize the histological structure of the studied tissues, the treated tissues were additionally stained with Meyer's hematoxylin (DAKO, Denmark) for 1-3 min. After that, the stained sections were placed in Eukitt ${ }^{\circledR}$ medium (Germany). To gain a better understanding, samples were subjected to a light microscope (Olympus AX70, Japan) with a digital camcorder (Olympus DP50, Japan) connected to a personal computer. This procedure aimed to determine the content, location, and number of 
lymphocyte subpopulations (per relative unit area with the magnification $\times 400$ ). Furthermore, qualitative marker expression was assessed in 10 randomly selected fields of histological section view with the magnification of $\times 400$, $\times 600, \times 800$, and $\times 1000$. Differentiation or immunoregulative index (ID) was determined as the quantitative ratio of lymphocytes with the antigenic determinants $\left(\mathrm{CD}^{+}: \mathrm{CD}^{+}\right)$. The microphotography of histological specimens was performed using a digital camera embedded in a Primo Star microscope (Carl Zeiss, Germany) and connected to a personal computer.

\section{Statistical analysis}

For data analysis, variational-statistical methods were performed using the Statistic 6.0 program (StatSoft Inc., USA) with regard to the peculiarities of statistical methods in biomedical studies (Horalskyi et al., 2011). Pvalue less than 0.05 was considered statistically significant.

\section{RESULTS}

\section{Anatomical studies}

The results of organometric investigations are indicated in Figure 1. As can be seen, the absolute weight (AW) of the thymus of chickens progressively increases as the chickens grow to 40 days of age. During 8-20 days of age, the AW of the thymus increases 18.4 times ( $\mathrm{p}<0.05$ ), and from 20 to 40 days of age, thymus AW increases 1.32 times $(p<0.05)$. Beginning at the age of 40 days, there is a rectilinear decrease in thymus AW by 3.78 times in 110day-old chickens (Figure 1).

The indicator of the relative weight of the thymus reached its maximum value in 20-day-old chickens. Over the next 20 days, the thymus AW increased, however, the thymus RW index decreased almost twice as much during this period $(\mathrm{p}<0.05)$. Therefore, the thymus acquires maximum morphological development in chickens by 20 and 40 days of age. By the age of 20 days, its weight increased in proportion to body weight. From 20 to 40 days of age, the rate of growth of the thymus decreases with a further morphological involution of this organ.

\section{Histological research}

The histological examination of the chicken's thymus revealed that the thymus is divided into the lobules of different sizes and shapes. Each of its lobules is surrounded by a thin connective tissue capsule made of collagen fibers. The capsule gives the separation membranes deep into the organ parenchyma. There was a differentiated cortex in each part of the thymus, massively filled with lymphocytes and medulla, with a much smaller number of lymphocytes (Figure 2). The medulla contained thymic corpuscles in the form of concentric accumulation of thickened epithelial cells.

The lobular structure of the thymus was expressed in 8-day-old chickens. In the cortex, lymphocytes were massively deposited, and reticuloepithelial cells were observed in some places. Lymphocytes and epithelial cells were observed in the medulla and thymic corpuscles represented by unicellular forms.

According to the results of morphometric examinations of 9-day-old chickens, the cortical area of the thymus was $35.51 \pm 0.31 \%$ and the medulla area was $55.58 \pm 0.34 \%$, accordingly the CI was estimated $0.65 \pm 0.02$. The connective tissue base occupied a small area and amounted to $8.91 \pm 0.38 \%$. The number of thymic corpuscles in the lobule was $4.5 \pm 0.06$ pieces (Table 1).

In the thymus of 20-day-old chickens, the cortex was shaped by tightly located lymphocytes, which in certain lobules formed wide layers of the cortex. The cortical area and $\mathrm{CI}$ in this age group were relatively small. In the medulla of 20-day-old chickens, there was the chaotic placement of the thymic corpuscles. Their number in one particle was $5.42 \pm 0.05$ pieces. In the medulla lobules, the processes of epithelial cells formed the mesh in the loops of which there were located lymphocytes and other cells (Figure 3).

At 20 days of age, the cortical area of the chickens' thymus increased to 1.16 times ( $\mathrm{p}<0.05$ ), compared to the previous age group. Moreover, and the medulla area decreased to 1.09 times and the CI was $0.81 \pm 0.01$ ( $\mathrm{p}<$ 0.05).

At 40 days of age, the cortical area of the thymic lobules of clinically healthy chickens increased significantly in comparison with the 20-day-old chickens and reached $48.84 \pm 0.74 \%(\mathrm{p}<0.05)$. The cortical area reduced to $35.36 \pm 0.36 \%(\mathrm{p}<0.05)$ and $\mathrm{CI}$ was $1.18 \pm$ 0.01 ( $\mathrm{p}<0.0501)$. The number of thymus calves increased and it was 6-9 pieces in each lobe with an average of $7.5 \pm$ 0.12 pieces (Table 1 ). The thymic corpuscles differed in size and shape. Some of them were optically dense, small, and homogeneous, whereas others were stratified and large (Figure 4). The microscopic structure of the thymus of 90-day-old chickens was similar to those of 40-day-old chickens. According to microscopic results, the cortex contained loose thymocytes, and there was a significant number of thymus bodies in the medulla (Figure 5). Their average number in the organ lobules was $9.43 \pm 0.13$ pieces $(\mathrm{p}<0.05$, table 1$)$. 
110-day-old chickens have the interlobular structure of the thymus which changed slightly compared to the previous age groups. The cortex consisted of loosely located thymocytes, medulla contained thymic corpuscles, the number of which was the largest, compared to all the other age groups, and amounted to $9.56 \pm 0.05$ pieces (Figure 6). The area of cortex decreased significantly $(42.57 \pm 0.89 \%, \mathrm{p}<0.05)$ with the medulla area reaching $31.26 \pm 0.17 \%$. The CI was measured $1.56 \pm 0.23(\mathrm{p}<$ 0.05 , table 1).

Therefore, histological studies showed that in the thymus of 40-day-old chickens, the cortex of the lobules forms wide layers and consists of tightly placed lymphocytes. As a result, there is a significant increase of $\mathrm{CI}$ in 1.46 and 1.82 times in 20 and 8-day-old chickens respectively. Such histological parameters of the chicken's thymus in this age characterize it as a morphologically mature organ.

\section{Immunohistochemical studies}

In the thymus of an 8-day-old chicken, the subpopulations of lymphocytes with markers $\mathrm{CD}^{+}$and $\mathrm{CD}^{+}$are seldomly located in the medulla and cortex of the thymus lobules. The cytomorphometric analysis revealed that the number of T-helper cells in chickens aged 8 days was $15.28 \pm 1.18$ pieces, and accordingly $\mathrm{T}$ cytotoxic cells amounted to13.61 \pm 1.21 pieces. The differentiation index (ID) was $1.13 \pm 0.27$ (Table 2).

In the medulla of 20-day-old chickens, thymus $\mathrm{CD} 8^{+}$ lymphocytes are located mostly solitary around the thymic corpuscles. In some cases, they form clusters in the form of "wedding rings" (Figure 7). Lymphocytes expressing the $\mathrm{CD}^{+}$marker are found in organ lobules both in medulla and cortex. There are more lymphocytes with markers $\mathrm{CD}^{+}$in medulla than in the cortex.

The number of such cells in the thymus of the chickens of this age increased in 2.48 times, compared to the previous age group, $\mathrm{CD}^{+}$in 1.5 times. The localization and location of T-lymphocytes with $\mathrm{CD} 8^{+}$ markers in the thymus of 40-day-old chickens was almost at the same level as in 20-day-old chickens. These cells are located loosely in the medulla and form clusters around the thymic corpuscles. Their loose content was observed in the cortex and in the interlobular connective tissue. Lymphocytes with $\mathrm{CD} 4^{+}$markers are located loosely and diffusely in both cortex and medulla and form focal clusters (Figure 8).

According to the results of cytoimmunohistochemical analysis, the number of lymphocytes expressing $\mathrm{CD}^{+}$antigen markers was increased in 40-day-old chickens, compared to the previous age group. At the same time the number of lymphocytes with $\mathrm{CD}^{+}$markers $(\mathrm{p}<0.05)$ increases 1.53 times (Table 2), and the ID of 40-day chickens was $1.26 \pm$ 0.09 .

The majority of lymphocytes with $\mathrm{CD} 8^{+}$markers are individually located around the lobules of the thymus in almost all chickens aged 90 and 110 days. Furthermore, they often form separate areas of round or elongated shape in the medulla of the thymus lobules or they may be found in the form of uniformly spaced single cells (Figure 9). They were also found around the thymic corpuscles.

Comparing the thymus of 90- and 110-day-old chickens with those in the previous age group, no significant difference was observed regarding the localization of T-lymphocytes with $\mathrm{CD} 4^{+}$markers (Figure 10). The number of lymphocytes with markers $\mathrm{CD}^{+}$in the thymus of 90-day chickens significantly increased in 4.95 pieces, compared to 40-day chickens $(\mathrm{p}<0.05)$. The number of lymphocytes with $\mathrm{CD} 8^{+}$markers remained almost unchanged. The ID of chickens was $1.52 \pm 0.25$ and $1.56 \pm 0.125$ when chickens aged 90 and 110 days, respectively ( $\mathrm{p}<0.05$, Table 2$)$.

Therefore, the immunohistochemical analysis indicated that there is a significant increase ( 1.53 times) of T-cytotoxic cells with the surface marker $\mathrm{CD} 8^{+}$in the thymus of 40-day chickens while comparing with the 20day bird and 2.29 times increase compared to the 8-dayold chickens. Lymphocytes expressing $\mathrm{CD}^{+}$surface markers also increased in 1.04 and 2.58 times, respectively. Such an increase in the number of lymphocytes with markers $\mathrm{CD} 8^{+}$and $\mathrm{CD} 4^{+}$correlates with changes in the thymus mass and may indicate the most pronounced functional activity of this organ at the relevant age period. 
Huralska et al., 2020

Table 1. Morphometric parameters of structural components in the chickens' thymus $(n=14)$

\begin{tabular}{|c|c|c|c|c|c|}
\hline \multirow{2}{*}{$\begin{array}{l}\text { Chicken } \\
\text { age (day) }\end{array}$} & \multicolumn{3}{|c|}{ Area $(\%)$} & \multirow{2}{*}{$\begin{array}{l}\text { Number of thymus } \\
\text { bodies in a lobule }\end{array}$} & \multirow{2}{*}{ Cortex index } \\
\hline & Cortex & Medulla & Connective tissue base & & \\
\hline 8 & $35.51 \pm 0.31$ & $55.58 \pm 0.34$ & $8.91 \pm 0.38$ & $4.5 \pm 0.06$ & $0.65 \pm 0.02$ \\
\hline 20 & $41.06 \pm 0.18^{*}$ & $50.89 \pm 0.34 *$ & $8.05 \pm 0.41$ & $5.42 \pm 0.05^{*}$ & $0.81 \pm 0.01 *$ \\
\hline 40 & $48.84 \pm 0.74 *$ & $35.36 \pm 0.36 *$ & $15.8 \pm 0.82^{*}$ & $7.5 \pm 0.12 *$ & $1.18 \pm 0.01 *$ \\
\hline 90 & $52.79 \pm 0.31 *$ & $30.84 \pm 0.48 *$ & $16.37 \pm 0.47$ & $9.43 \pm 0.13 *$ & $1.43 \pm 0.02 *$ \\
\hline 110 & $42.57 \pm 0.89 *$ & $31.26 \pm 0.17$ & $26.17 \pm 0.96^{*}$ & $9.56 \pm 0.05$ & $1.56 \pm 0.23^{*}$ \\
\hline
\end{tabular}

$* \mathrm{p}<0.05$ in relation to the previous age group; Data are presented as Mean \pm Standard Error of Mean

Table 2. The number of lymphocyte subpopulations in the thymus of chickens at different ages

\begin{tabular}{lccc}
\hline \multirow{2}{*}{ Age (day) } & \multicolumn{2}{c}{ CD4 $^{+}$} & CD8 \\
\cline { 2 - 3 } & \multicolumn{2}{c}{ Units area (x400), pcs. } & $1.13 \pm 0.27$ \\
\hline 8 & $15.28 \pm 1.18$ & $13.61 \pm 1.21$ & $1.86 \pm 0.29^{*}$ \\
20 & $37.94 \pm 0.69^{*}$ & $20.44 \pm 1.03^{*}$ & $1.26 \pm 0.09^{*}$ \\
40 & $39.44 \pm 1.59$ & $31.28 \pm 1.51^{*}$ & $1.52 \pm 0.25^{*}$ \\
90 & $44.39 \pm 2.02^{*}$ & $29.11 \pm 1.07$ & $1.56 \pm 0.15$ \\
110 & $45.56 \pm 1.42$ & $29.28 \pm 1.41$ & \\
\hline
\end{tabular}

"p $<0.05$; Data are presented as Mean \pm Standard Error of Mean

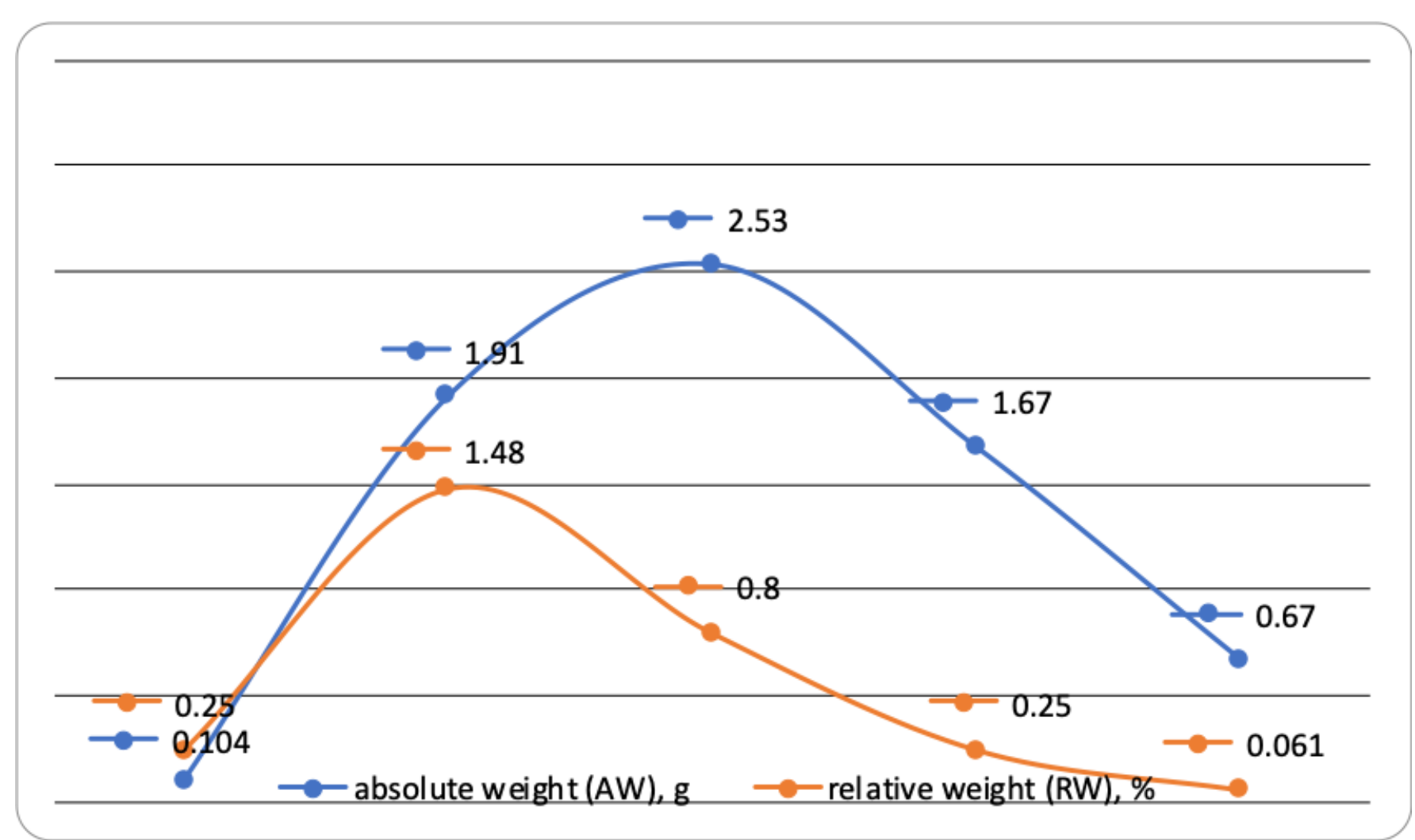

Figure 1. Dynamics of the absolute and relative weight of the chickens' thymus 


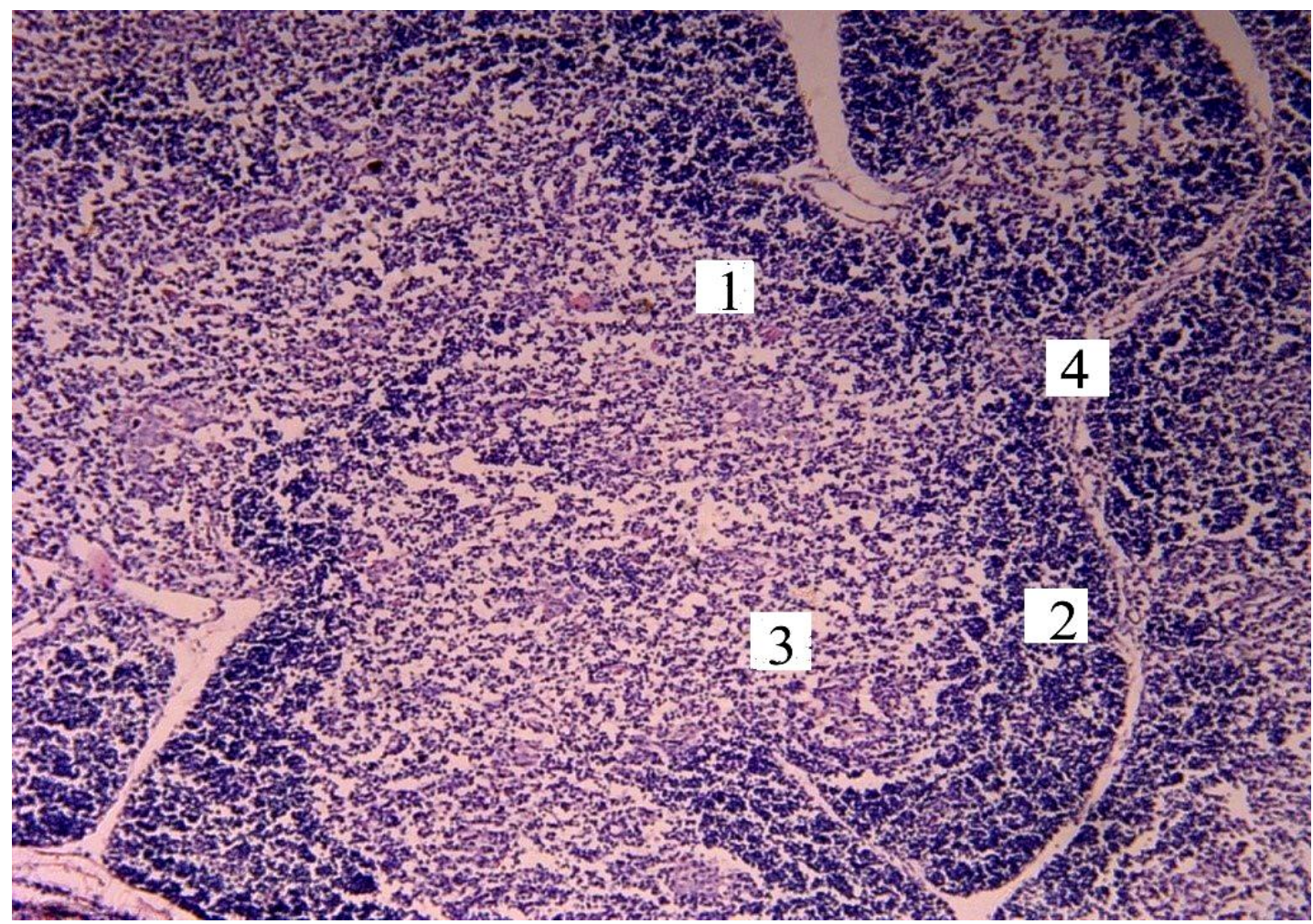

Figure 2. Microscopic thymus structure of the 8-day-old chicken of Haysex Brown cross. 1: Thymus lobule, 2: cortex, 3: Medulla, 4: Interlobular connective tissue, $\mathrm{H} \& \mathrm{E} \times 100$

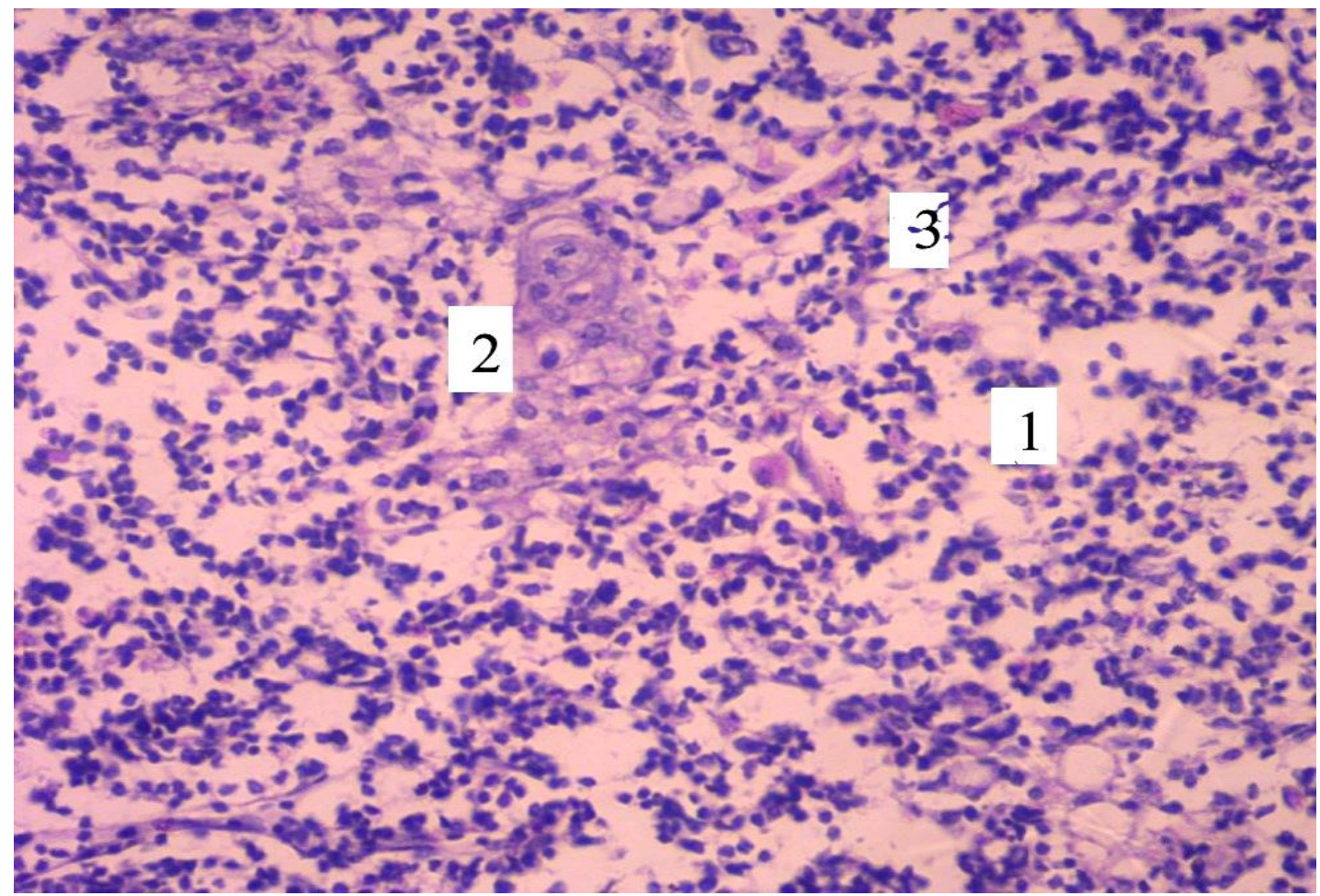

Figure 3. Microscopic thymus structure of a 20-day-old chicken of Haysex Brown cross.1: Medulla, 2: Thymic corpuscles, 3: Growing up epitheliocytes, $H \& E \times 400$ 


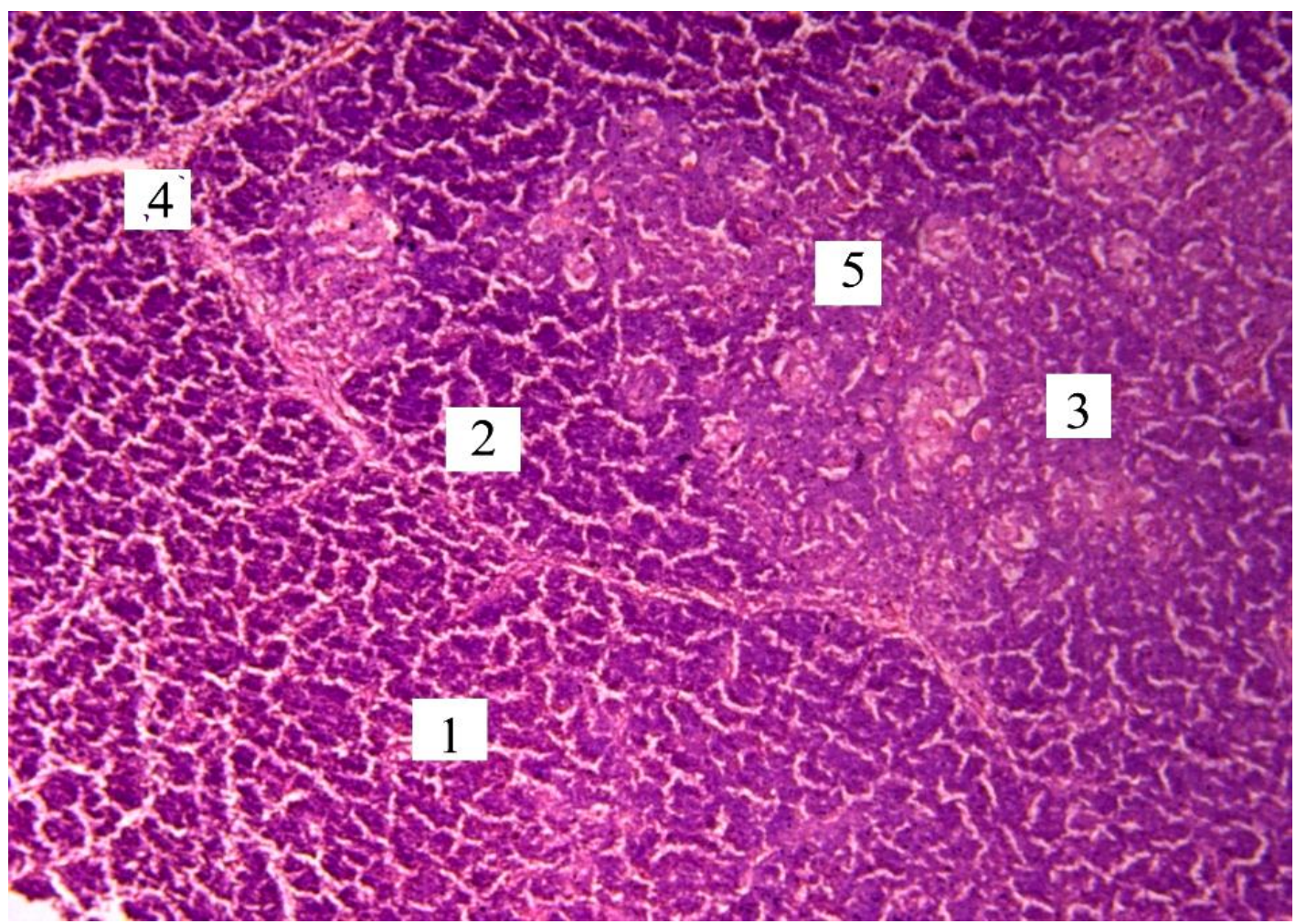

Figure 4. Microscopic thymus structure of a 40-day-old chicken of Haysex Brown cross (1: thymic lobule, 2: cortex, 3: medulla, 4: interlobular connective tissue, 5: thymic corpuscles. H\&E x 100)

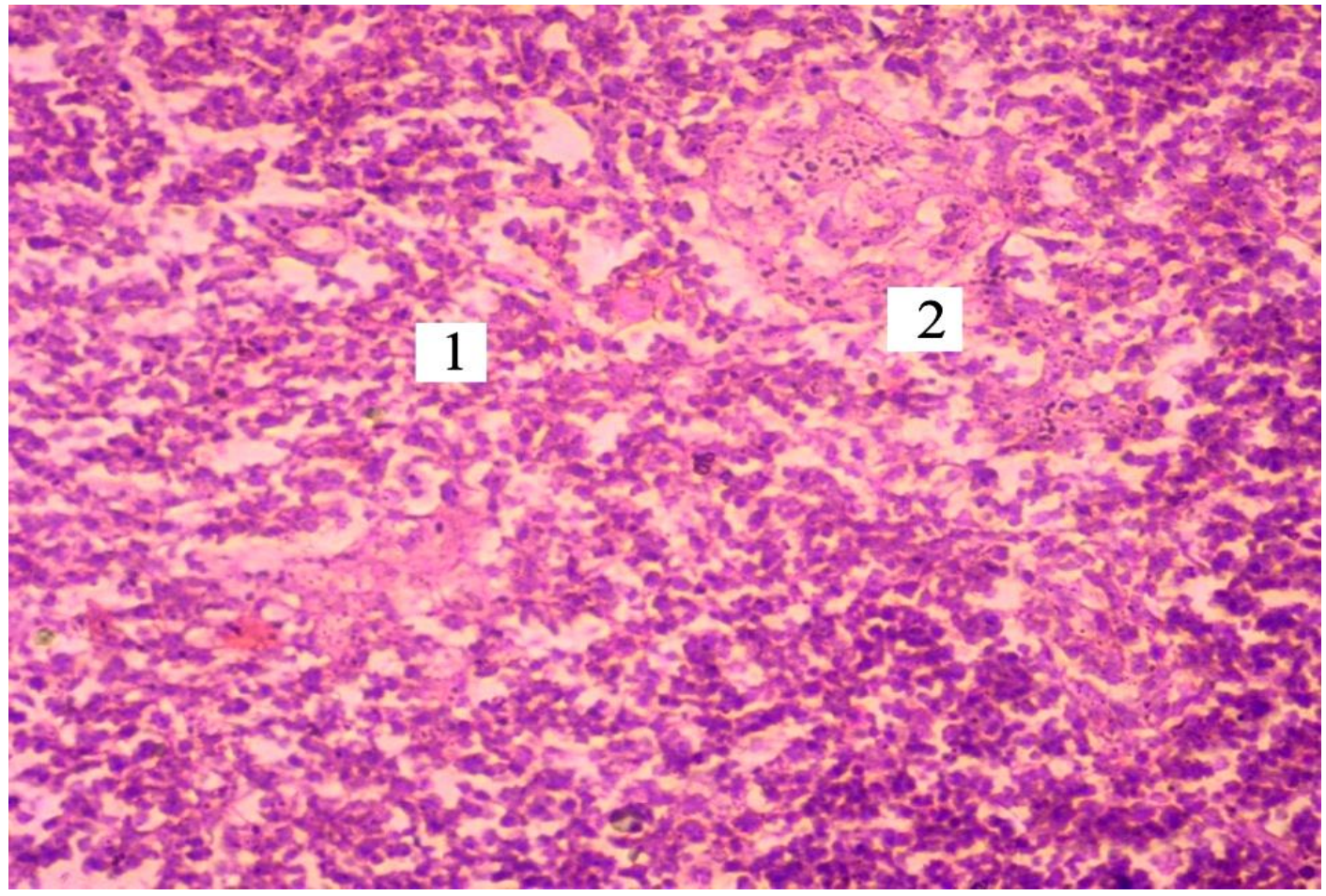

Figure 5. Microscopic structure of the thymus of the 90-day-old chicken of Haysex Brown cross.1: Medulla; 2: Thymic corpuscles, H\&E $\times 400$ 


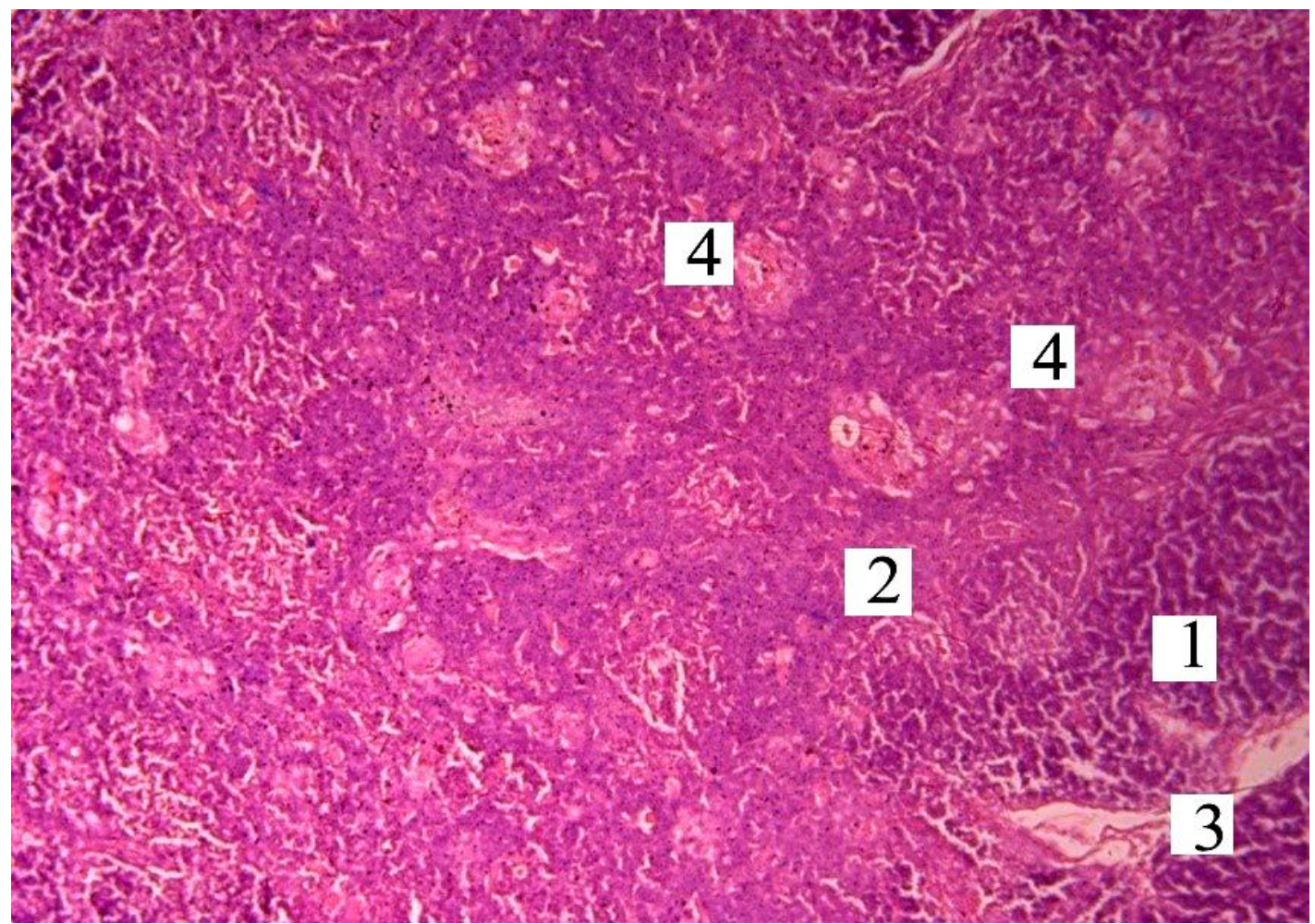

Figure 6. Microscopic thymus structure of a 110- day-old chicken of Haysex Brown cross (1: Cortex, 2: Medulla, 3: Interlobular connective tissue, 4: Thymic corpuscles, $H \& E \times 100$ )

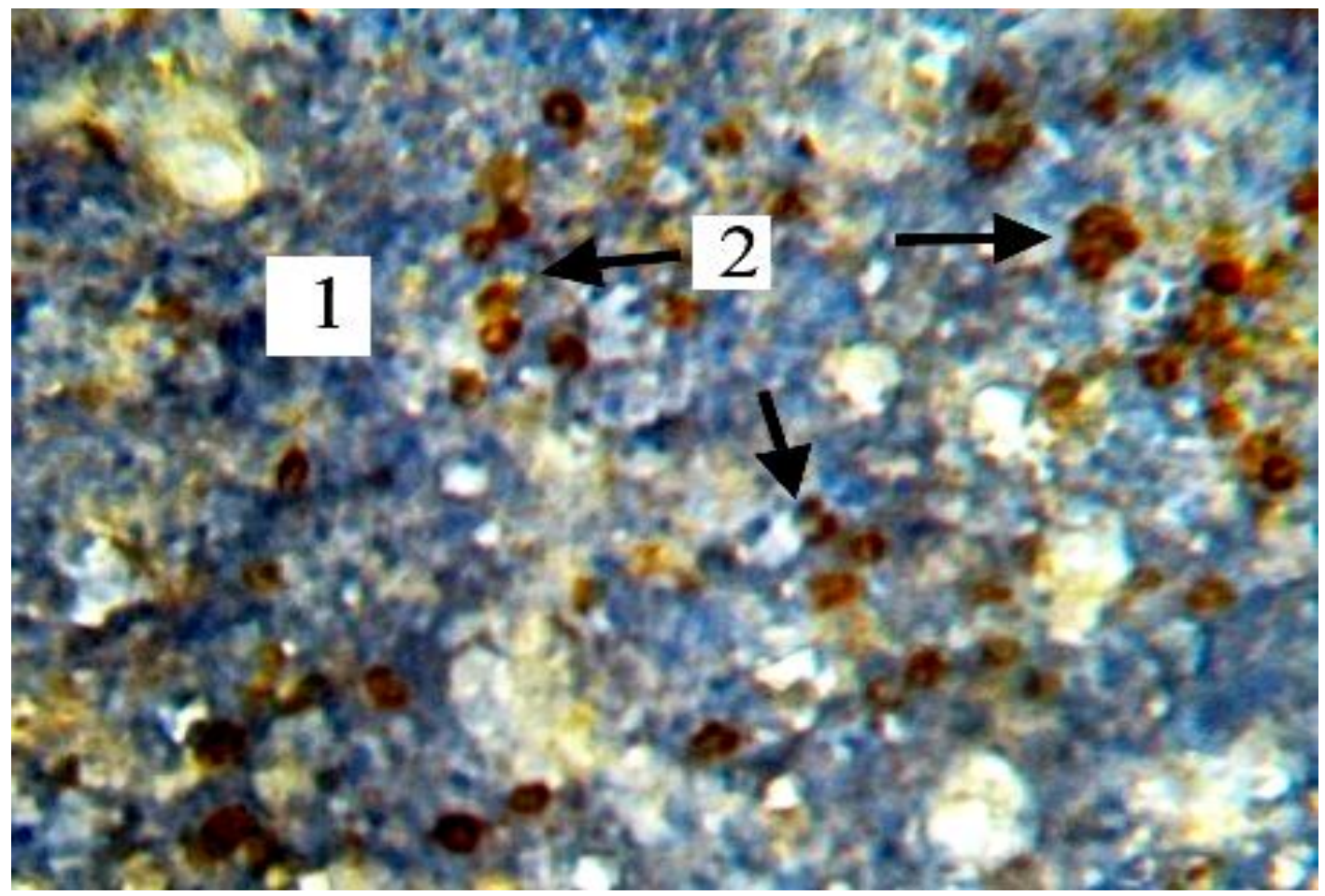

Figure 7. The $\mathrm{CD}^{+}$lymphocytes in the thymus of a 20-day-old chicken of Haysex Brown cross.1: Medulla; 2: $\mathrm{CD} 8^{+}$Lymphocytes. Histopreparations using monoclonal antibodies with additional fine-tuning of Mayer's hematoxylin, $\times 600$ 


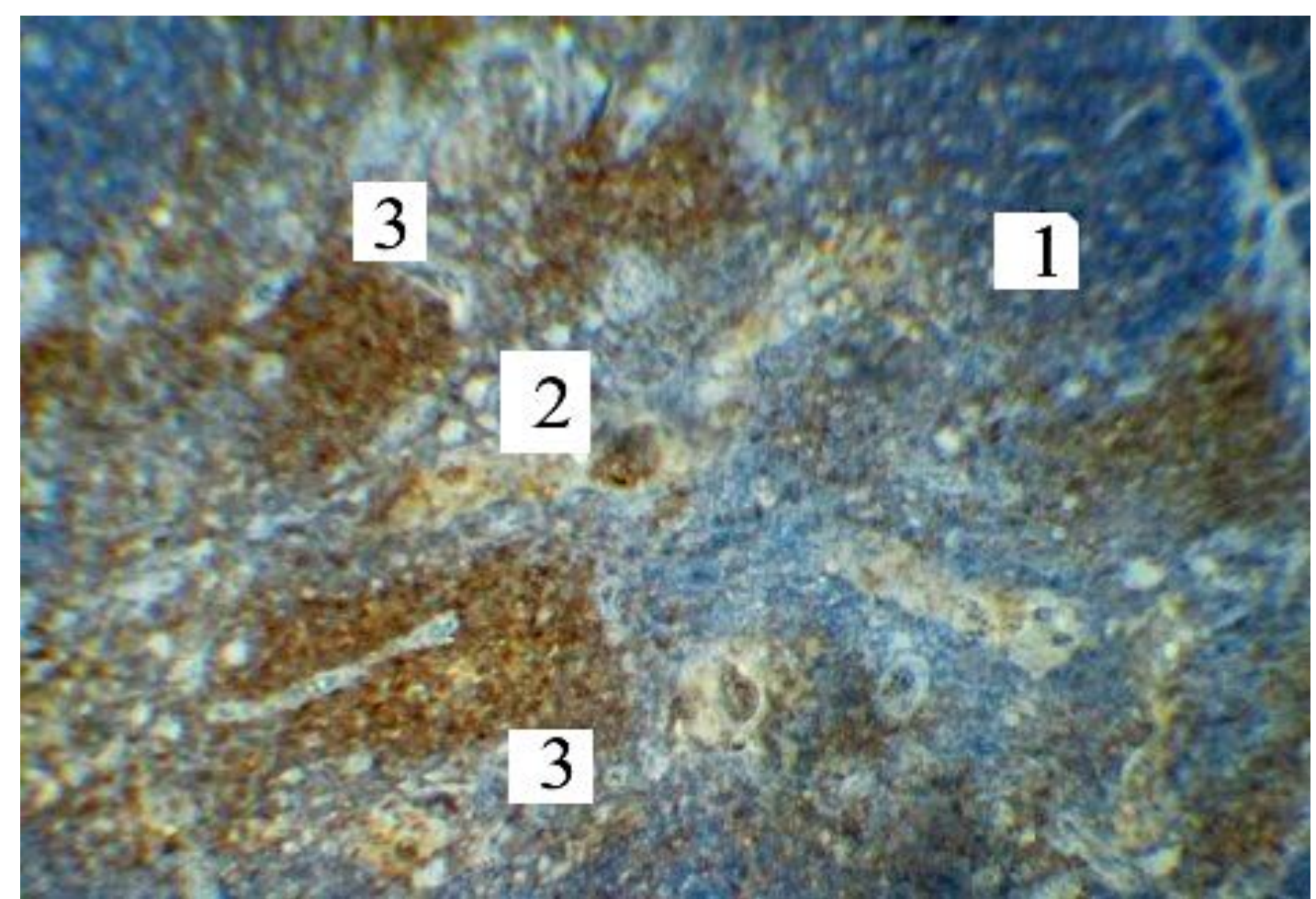

Figure 8. $\mathrm{CD}^{+}$lymphocytes in the thymus of a 20-day-old chicken of Haysex Brown cross. 1: Cortex, 2: Medulla, 3: Focal clusters of $\mathrm{CD}^{+}$lymphocytes. Histopreparations using monoclonal antibodies with additional fine-tuning by Mayer's hematoxylin, $\times 100$

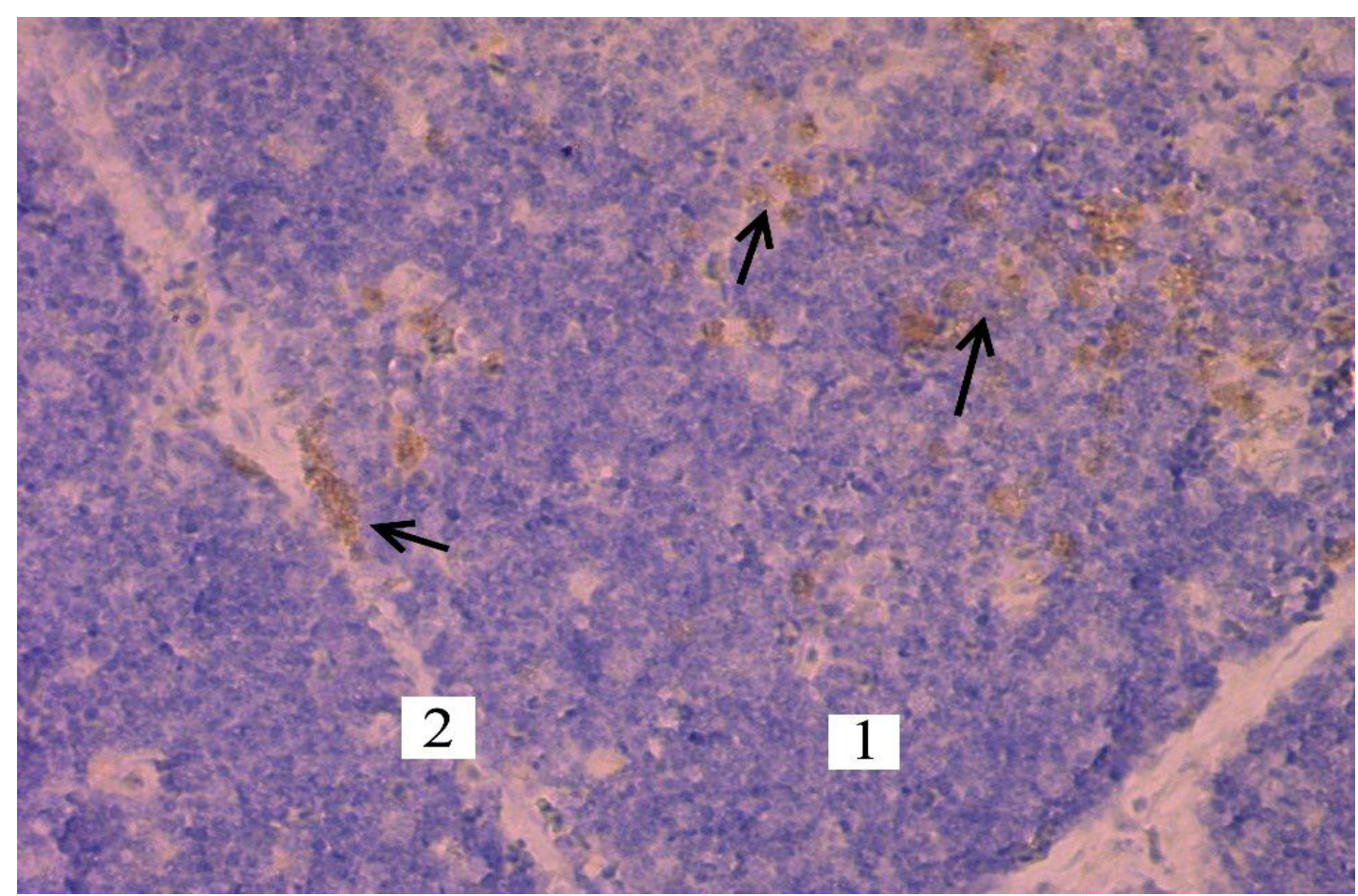

Figure 9. The $\mathrm{CD} 8^{+}$lymphocytes (arrows) in the thymus of a 90-day-old chicken of Haysex Brown cross 1: Thymic lobule, 2: Interlobular connective tissue. Histopreparation are presented using monoclonal antibodies with additional fine-tuning of Mayer's hematoxylin $\times 400$ 


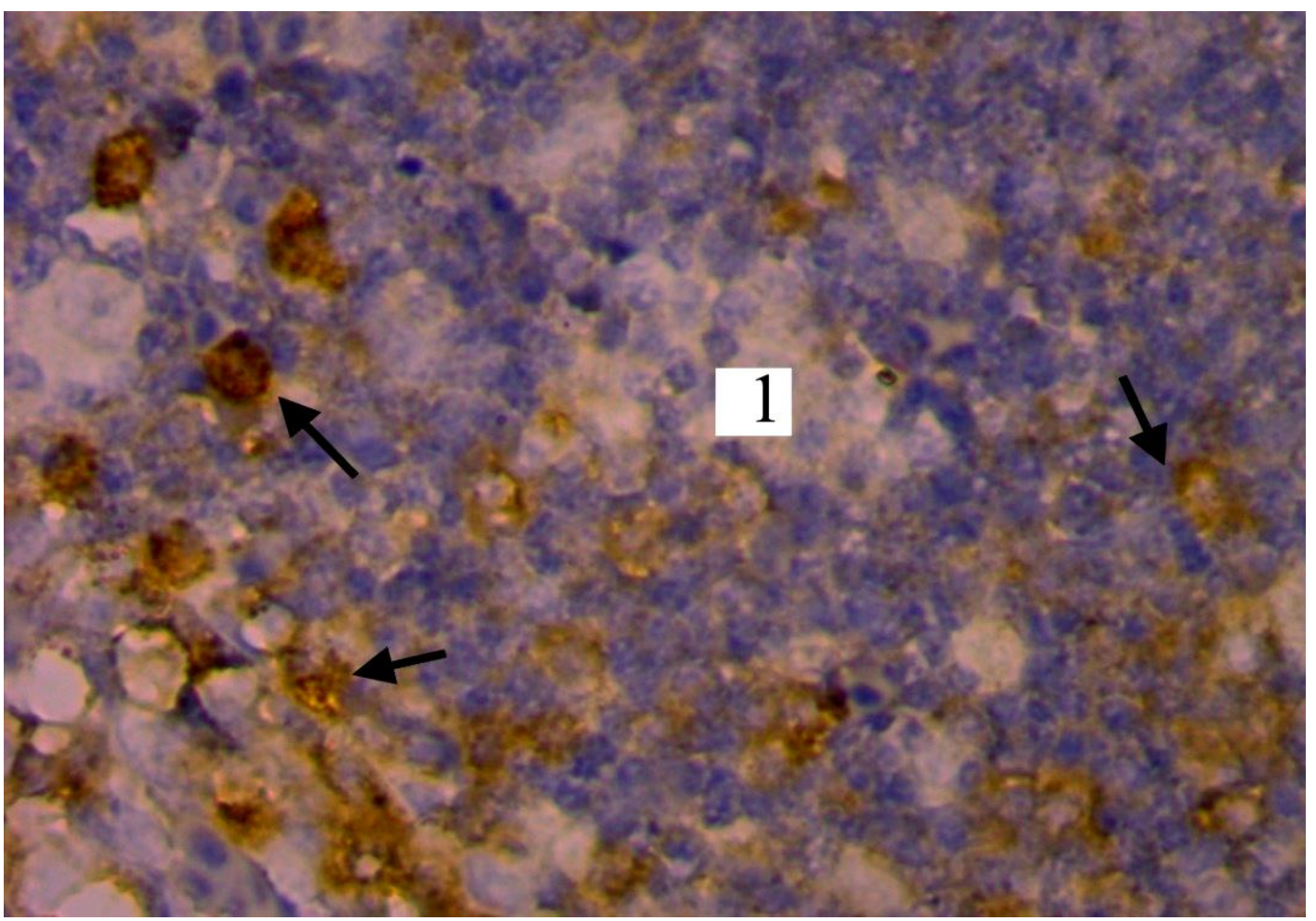

Figure 10. The $\mathrm{CD}^{+}$lymphocytes (arrows) in the thymus of a 110-day-old chicken of Haysex Brown cross. 1: Cortex. Histopreparations are presented using monoclonal antibodies with additional fine-tuning of Mayer's hematoxylin, $\times 1000$

\section{DISCUSSION}

Considering the evaluation of the avian immune system, there is a need to pay great concerted attention to the condition of the organs involved in their immune system (e.g., thymus, cloacal bursa, and spleen). Despite a number of studies addressing the morphology of lymphoid organs, there are still questions about the dynamics of the development of immunocompetent organs in the postnatal ontogeny and the timing of their involution onset. Understanding the morphological features of the thymus and their changes are important for the functional evaluation of the immune system (Pearse, 2006).

It has been found that with the growth and development of young animals, the absolute and relative weight of the thymus increases (Bellamy, 1982), and these indicators significantly decrease with the puberty, especially in the case of the onset of sexual activity of the bird (Ciriaco et al., 2003). At the time, an involution of the thymus mass and cortical area develops and the boundary between the cortex and medulla matter is shrunk. There is a change in the cellular composition of the thymus where cortex becomes thinner and involution takes its place (Haseeb et al., 2014). Age involution is characterized by a decrease in the amount of lymphoid tissue and the production of T-lymphocytes. However, the total content of circulating T-lymphocytes is maintained at the achieved level since this population of T-lymphocytes represents long-living cells with no requirement of a permanent restoration (Rezzani et al., 2008; Hui, 2012). This leads to the changes in cortex and medulla ratio and proliferation of connective stroma and adipose tissues (Haseeb et al., 2014). One of the reasons for the early onset of organ involution may be the stress factors (Hussan et al., 2009). According to some authors, the degree of its development and morphological condition of thymus significantly affects body's resistance to infections (Treesh et al., 2014).

According to present study, the growth and development of the thymus continue gradually during the first 90 days of birds' life. However, the growth and development of the relative weight of the thymus in broiler chickens take place during the first seven weeks (Tarek, 2012). According to present data, the relative weight of the thymus at 40 days of age is around $0.80 \pm 0.03 \%$, which is probably due to the individual characteristics of chickens' development, maintenance conditions, and breeding properties. 
The obtained results of the current study addressing the morphological characteristics of the thymus on cellular and tissue levels are supported by many authors (Akter et al., 2006; Haseeb et al., 2014; Senapati et al., 2015; Ali et al., 2017; Kanasiya et al., 2018). It was found that 8-dayold chickens have already fully formed the structural elements of the thymus. Thus, 8-day-old chickens have partly expressed structure with the CI of $0.65 \pm 0.02$. The dense arrangement of lymphocytes was established in the cortex of thymic corpuscles and reticulospinal cells were found in some places. Lymphocytes and epithelial cells were also observed in the medulla of thymic lobules, and thymic corpuscles were presented by the unicellular forms. These findings confirm the previous studies conducted by many authors. Akter et al. (2006), Khan et al. (2014), Biben (2015), and Ali et al. (2017) described the lobe structure of the thymus by differentiating cortex (densely packed with lymphocytes) and medulla (with a fewer number of lymphocytes) in each lobule.

The present results were also in line with the data obtained by Biben's (2015) indicating that 3-week-old chickens have epithelial cells in thymus medulla at various stages of maturation and apoptosis. This means a normal physiological process testified about the activation of the processes in the immune system. Thymic corpuscles are well-developed and clearly defined which feature the physiological processes of cell death (Biben, 2015). The findings of the present study showed the chaotic placement of thymic corpuscles in the thymus medulla of 20-day chickens. Their number in one slice was $5.42 \pm$ 0.05 pieces. In the same vein, Soad et al. (2014) observed a significant increase in thymic corpuscles in 6- and 8week-old chickens. Khalil et al. (2003) also reported the growth of thymic corpuscles as birds grow older. The obtained results of the present study demonstrated the growth of thymic corpuscles among chicken aged up to 90 days.

T-system of birds takes part in forming the immune response and regulates its duration (Rezzani et al., 2008). Although an increased number of CD4+, CD8+ T cells were observed in peripheral blood during virus infections, there is a dearth of research on their role, function, and biological significance (Cui et al., 2004; Nascimbeni et al., 2004). Bridle et al. (2006) identified an increase of CD4 and CD8 T-cells population in the 8-week-old chickens. In present study, it was observed that the ID of the thymus of 8-day-old chickens was $1.13 \pm 0.27$ indicating the existence of immune defense cells at the end of the prenatal development. However, the thymus ID of 20-day-old chickens had the highest value among the investigated age groups reaching $1.86 \pm 0.29$.

Erf et al. (1998) observed an increase in the ratio of CD4:CD8 in chickens thymus with age. This ratio was reported 1.20 and 2.30 for 2-week-old and 7-week-old chickens, respectively. Similar changes in CD4:CD8 ratio of chicken's thymus was observed in a study conducted by Kannan et al. (2017). The authors of this study reported an increase of the ratio to 0.67 and 0.72 for 4 and 8 week-old chickens respectively. According to the findings of the present research, the ID of 40-day-old chickens was reported 1.26 \pm 0.09 , whereas, this estimation was $1.52 \pm 0.25$ and $1.56 \pm 0.23$ in the 90 and 110-day-old chickens, respectively.

Accordingly, the obtained results of the current study were indicative of CD4:CD8 ratio growth during the bird's aging process. In addition, it was found that the growth of $\mathrm{T}$ lymphocytes quantity $\left(\mathrm{CD} 8^{+}\right.$and $\left.\mathrm{CD} 4^{+}\right)$can be observed in older chickens, in particular those at 20- and 40-days of age. In this period, there was a significant increase in the absolute weight of the thymus and cortical area. Thus, an investigation into the composition of the lymphocyte markers $\mathrm{CD}^{+}, \mathrm{CD}^{+}$in the thymus of healthy chickens is promising since it enriches the existing literature about cytoarchitectonics, growth, and development of the thymus in chickens during the postnatal period of ontogenesis.

\section{CONCLUSION}

Thymus acquires maximum morphological development in 40-day-old chickens. During this period, there was an increase in the number of lymphocytes with $\mathrm{CD}^{+}$and $\mathrm{CD}^{+}$markers. The findings correlate with the changes in thymus mass, cortical area, and the cortex index indicating the highest level of expressed functional activity of this organ during this period. The data can yield new insights into developing preventive vaccination schemes.

\section{DECLARATIONS}

\section{Author's contributions}

Svitlana Huralska and Tetiana Kot created the idea and designed the study, and wrote the draft of manuscript. Vasyl Sokolyuk and Zoriana Khomenko collected data and performed the statistical analysis. Vasyl Koziy collected the information and revised the manuscript. All 
authors checked and confirmed the final version of the manuscript.

\section{Competing interests}

The authors have declared no competing interest.

\section{REFERENCES}

Akter SH, Khan MZI, Jahan MR, Karim MR and Islam MR (2006). Histomorphological study of the lymphoid tissues of broiler chickens. Bangladesh Journal of Veterinary Medicine, $\quad 4 \quad$ (2): 87-92. DOI: https://doi.org/10.3329/bjvm.v4i2.1289.

Ali HK (2017). Histomorphological study of thymus in local chicken "Gallus gallusdomesticus". Diyala Journal for Pure Sciences, 13 (3): 120-132. DOI: https://doi.org/10.24237/djps.1303.294A.

Bellamy D and Mohamed K (1982). A comparative study of age involution of the bursa of Fabricius and thymus in birds. Thymus, 4(2): 107-114. Available at: https://www.ncbi.nlm.nih.gov/pubmed/7064199.

Biben IA (2015) Influence probiotic cultures of Aerococcusviridans strain BI-07 on morphology of the immune system broiler chickens. Scientific and Technical Bulletin of the State Research Institute of Veterinary Drugs and Feed Additives and the Institute of Animal Biology, 16 (2): 181-187. Available at: http://nbuv.gov.ua/UJRN/Ntbibt_2015_16_2_31.

Bridle BW, Julian R, Shewen PE, Vaillancourt JP and Kaushik AK (2006). T lymphocyte subpopulations diverge in commercially raised chickens. Canadian Journal of Veterinary Research, 70: 183-190. Available at: https://www.ncbi.nlm.nih.gov/pmc/articles/PMC1477934.

Ciriaco E, Pinera PP, Diaz-Esnal B and Laura R (2003). Agerelated changes in the avian primary lymphoid organs (thymus and bursa of Fabricius). Microscopy Research and Technique, 62 (6): 482-487. Doi: https://doi.org/10.1002/jemt.10416.

Cui H, Xi P, Junliang D, Debing L and Guang Y (2004). Pathology of lymphoid organs in chickens fed a diet deficient in zinc. Avian Pathology, 33(5), 519-524. DOI: https://doi.org/10.1080/03079450400003528.

Erf GF, Botje WG and Bersi TK (1998). CD4, CD8 and TCR defined $\mathrm{T}$ cell subsets in thymus and spleen of 2 and 7 week-old commercial broiler chickens. Veterinary Immunology and Immunopathology, 61: 320-332. DOI: https://doi.org/10.1016/s0165-2427(97)00070-6.

Franchini A, Marchesini E and Ottaviani E (2004). Corticosterone 21-acetate in vivo induces acute stress in chicken thymus: cell proliferation, apoptosis and cytokine responses. Histology and Histopathology, 19(3): 693-699. DOI: https://doi.org/10.14670/HH-19.693.

Haseeb A, Shah MG, Gandahi JA, Lochi GM, Khan MS, Faisal M, Kiani FA, Ali mangi R and Oad SK (2014). Histomorphological Study on Thymus of Aseel chicken. Journal of Agriculture and Food Technology, 4(2): 1-5. Available at: https://www.researchgate.net/publication/263620260.
Horalskyi LP, Khomych VT and Kononskyy OI (2011). Fundamentals of histological technology and morphofunctional methods of research in norm and pathology. Polissya, Zhytomyr, p. 288.

Hussan MT, Khan MZI and Lucky NS (2009). Immunohistochemical study of the postnatal development of lymphoid tissues and mucosa of broilers. Bangladesh Journal of Veterinary Medicine, 7(1): 253-258. DOI: https://doi.org/10.3329/bjvm.v7i1.5069.

Kanasiya S, Karmore SK, Gupta SK, Barhaiya RK and Rokde K (2018). Histomorphological characterization of the thymus gland in Kadaknath. Global Journal of Bio-Science and Biotechnology, 7 (3): 396-399. Available at: http://www.scienceandnature.org/GJBB_Vol7(3)2018/GJB B-V7(3)2018-16.pdf.

Kannan TA, Ramesh G, Ushakumari S, Dhinakarraj G and Vairamuthu S (2017). Age Related Changes in T Cell Subsets in Thymus and Spleen of Layer Chicken (Gallus domesticus). International Journal of Current Microbiology and Applied Sciences, 6(1): 15-19. DOI: https://doi.org/10.20546/ijcmas.2017.601.002.

Kannan TA, Ramesh G, Ushakumari S, Dhinkarraj G and Vairamuthu S (2015). Electronmicroscopic studies of thymus in chicken (Gallus domesticus). International Journal of Veterinary Science, 4: 171-174. Available at: https://www.cabdirect.org/cabdirect/abstract/20163032733.

Khalil M, Khan ZI, Khalil M and Islam R (2003). A prospective study of prenatal and postnatal development of thymus of Deshi chicken. Mymensingh Medical Journal, 12(1): 2024. Available at: https://www.ncbi.nlm.nih.gov /pubmed/12715637.

Khan MZI, Masum M, Khan ZI, Aziz ARB, Nasrin M, Siddique MNH and Arshad MMB (2014). Histomorphology of the lymphoid tissues of broiler chickens in Kelantan, Malaysia (Histomorfologi Tisu Limfa Ayam Pedaging di Kelantan, Malaysia). SainsMalaysiana, 43(8): 1175-1179. Available at: https://www.researchgate.net/publication/ 289262788.

Li Y, Lei X, Lu H, Guo W, Wu S, Yin Z, Sun Q and Yang X (2018). Age-related changes on CD40 promotor methylation and immune gene expressions in thymus of chicken. Frontiers in Immunology, 21(9): 2731. DOI: https://doi.org/10.3389/fimmu.2018.02731.

Mullakaev AO, Lezhnina MN and Shukanov AA (2013). Structure and function of immunocompetent organs in broilers. Bulletin of Experimental Biology and Medicine, 155(1): 96-8. DOI: https://doi.org/ 10.1007/s10517-0132089-1.

Nascimbeni M, Shin EC, Chiriboga L, Kleiner DE and Rehermann B (2004). Peripheral $\mathrm{CD}^{+} \mathrm{CD}^{+} \mathrm{T}$ cells are differentiated effector memory cells with antiviral functions. Blood, 104: 478-486. DOI: https://doi.org/10.1182/blood-2003-12-4395.

Oubre CM, Zhang X, Clements KE, Porter TE and Berghman LR (2004). Immunohistochemical assessment of the neurosecretory cells of the chicken thymus using a novel monoclonal antibody against avian chromogranin A. Developmental and Comparative Immunology, 28(4): 337345. DOI: https://doi.org/10.1016/j.dci.2003.08.008. 
Pearse G (2006). Normal structure, function and histology of the thymus. Journal of Toxicologic Pathology, 34: 504-514. DOI: https://doi.org/10.1080/01926230600865549.

Rezzani R, Bonomini F and Rodella LF (2008). Histochemical and molecular overview of the thymus as site for T-cells development. Progress in Histochemistry and Cytochemistry, 43(2): 73-120. DOI: https://doi.org/10.1016/j.proghi.2008.03.001.

Rieker T, Penninger J, Romani N and Wick G (1995). Chicken thymic nurse cells: an overview. Developmental \& Comparative Immunology, 19(4): 281-289. DOI: https://doi.org/10.1016/0145-305x(95)00008-h.

Senapati MR, Behera PC, Maity A and Mandal AK (2015). Comparative Histomorphological Study on the thymus with reference to its immunological importance in quail, chicken and duck. Exploratory Animal and Medical Research, 5(1): 73-77. Available at: https:// pdfs.semanticscholar.org/cdd1/f9b2e00b15c21dddfbbf470 3e9ba3c78f4a2.pdf.

Sharma JM (1999). Introduction to poultry vaccines and immunity. Advances in Veterinary Medicine, 41: 481-494. DOI: https://doi.org/10.1016/s0065-3519(99)80036-6.
Song H, Peng K, Li S, Wang Y, Wei L and Tang L (2012). Morphological characterization of the immune organs in ostrich chicks. Turkish Journal of Veterinary and Animal Sciences, 36(2): 89-100. DOI: https://doi.org/10.3906/vet0910-128.

Tarek K, Mohamed M, Omar B and Hassina B (2012). MorphoHistological Study of the Thymus of Broiler Chickens During Post-Hashing Age. International Journal of Poultry Science, $\quad 11 \quad$ (1): $\quad 78-80 . \quad$ DOI: https://doi.org/10.3923/ijps.2012.78.80.

Treesh SA, Buker AO and Khair NS (2014). Histological, histochemical and immunohistochemical studies on thymus of chicken. International Journal of Histology and Cytology, 1(11): 103-111. Available at: https://pdfs.semanticscholar.org/fc29/be00e88743c090c74 668055be88e97e352fc.pdf.

Wang Y, Jiang L, Li Y, Luo X and He J (2016). Effect of Different Selenium Supplementation Levels on Oxidative Stress, Cytokines, and Immunotoxicity in Chicken Thymus. Biological Trace Element Research, 172(2): 488495. DOI: https://doi.org/10.1007/s12011-015-0598-7. 